\title{
Comparative study of three tests (dye test, indirect haemagglutination test, latex agglutination test) for the detection of antibodies to Toxoplasma gondii in human sera
}

\author{
ALAN H BALFOUR, * DG FLECK, $\dagger$ HUW PA HUGHES, $\ddagger$ D SHARP $\dagger$ \\ From the *Regional Public Health Laboratory, Bridle Path, York Road, Leeds LS15 7TR, the †Public Health \\ Laboratory, St George's Hospital, Blackshaw Road, London SW17 OQT, and the $\ddagger$ Department of Pure \\ and Applied Zoology, The University, Leeds LS2 9JT
}

SUMMARY An evaluation has been made of a commercial latex agglutination test, Toxotest-MT (TMT) (Eiken, Japan), for the detection of antibodies to Toxoplasma gondii in human sera. In qualitative studies, 878 sera were examined in both the TMT and dye test (DT) and $96.6 \%$ agreement was found. In quantitative studies 339 sera were titrated in the TMT and DT, with 337 of these sera also titrated in the indirect haemagglutination test (IHAT). Agreement between the DT and TMT was best, $78 \%$ of the sera showing titres within \pm 1 dilution in the two tests. The IHAT and TMT gave $66 \%$ agreement, while the DT and IHAT showed least agreement, $40.9 \%$.

The results suggest that the pattern of antigenic determinants to which antibody levels are measured are different in the three test systems. The TMT is a better substitute for the DT than the IHAT.

The method of choice in the serodiagnosis of infections due to Toxoplasma gondii is still the dye test (DT) of Sabin and Feldman (1948). ${ }^{1}$ The test has undergone many subsequent modifications and is now carried out in microtitre plates ${ }^{2}$ and the results can be read directly using an inverted microscope. ${ }^{3}$ The need for live parasites and suitable human serum as a source of accessory factor severely limits the availability of the DT and has led to a continuing search for an alternative test which is equally effective but less exacting.

The indirect immunofluorescence test has been extensively evaluated and been found satisfactory in comparison to the dye test. ${ }^{4}$ However, facilities for fluorescent microscopy and a skilled operator to read and interpret the results are required with this technique.

An indirect haemagglutination test (IHAT) using sheep red cells as an antigen carrier was described by Jacobs and Lunde. ${ }^{5}$ The test was both sensitive and specific and has been further developed. ${ }^{6-9}$ Reagents are commercially available in kit form from several manufacturers and are widely used on a routine basis. However, recent work ${ }^{10}$ has shown that the IHA test can fail to detect early infections,

Accepted for publication 15 July 1981 and the IHAT is of only limited value in determining the stage of progression of a $T$ gondii infection. ${ }^{11}$

The use of latex as an antigen carrier in a slide agglutination test was described ${ }^{12}$ but subsequent experience with the test showed a lack of sensitivity with inconsistency between batches.

More recently a latex agglutination test for use in the microtitre system has been described ${ }^{13}$ which allows quantitative as well as qualitative assessment of antibody levels to a $T$ gondii antigen coated on to the particles. This test kit, produced by the Eiken Chemical Co of Japan (Toxotest-MT) is available from Diamed Diagnostics Ltd, Mast House, Derby Road, Bootle, Merseyside, L20 1EA.

We had studied and evaluated the Toxotest-MT (TMT) kit by comparing it with the DT and IHAT.

\section{Material and methods}

DYE TEST

The dye test (DT) was performed in flat-bottomed microtitre plates and read directly using an inverted microscope, ${ }^{3}$ a modification of the test described by Sabin and Feldman ${ }^{1}$ and Feldman and Lamb. ${ }^{2}$ The test was standardised against the Toxoplasma National Control Serum, produced at the Public Health Laboratory, Tooting, which in turn has been 
standardised against the WHO International Control Serum, issued by the State Serum Institute, DK-2300, Copenhagen, S Denmark.

INDIRECT HAEMAGGLUTINATION TEST

The indirect haemagglutination test (IHAT) was performed as described for the ToxHa-test kit supplied by Wellcome Reagents Ltd, in which turkey red cells sensitised with $T$ gondii antigen are used. Each serum was also tested with unsensitised cells to check for non-specific reactions. A positive serum of known titre together with a negative serum were run with each batch of tests for control purposes, as well as a sensitised cell control run without serum.

\section{TOXOTEST-MT (EIKEN)}

The Toxotest-MT (TMT) is an indirect latex agglutination test produced by the Eiken Chemical Company, Bonkyo, Tokyo, Japan. It was supplied as a compact kit containing $12 \mathrm{ml}$ of latex suspension sensitised with a $T$ gondii antigen, $50 \mathrm{ml}$ of buffer and $0.5 \mathrm{ml}$ of a freeze-dried positive control serum of known titre. If the latex antigen is used as recommended-that is, $25 \mu$ l per well, sufficient is provided for 480 wells. The kit has a shelf life of up to 12 months when stored at $2-10^{\circ} \mathrm{C}$. The test is relatively inexpensive with an estimated cost of less than $5 p$ per antigen well. Kits were supplied on a continuing basis so that different antigen batches were used in the course of the study.

The test was performed in microtitre plates (U-shaped wells). An initial 1/8 dilution of the serum was prepared using the buffer supplied and then doubling dilution set up from 1/16 to 1/16 384 using a pickup volume of $25 \mu \mathrm{l}$ and delivering this into a further $25 \mu$ l of diluent, $25 \mu$ l of sensitised latex was then added to each well. The positive control serum of known titre and an antigen control well (25 $\mu$ l of latex $+25 \mu$ l of diluent) were run with each batch of test sera.

After mixing, the plates were covered and left at room temperature overnight before the agglutination patterns were read against a black background.

In expressing titres in the TMT allowance was not made for dilution due to the addition of the antigen suspension. The end point was taken as the highest serum dilution showing significant agglutination. In the absence of specific antibody a compact button was obtained.

\section{Results}

A total of 878 human sera submitted for routine toxoplasma serology were examined in both the dye test and the Toxotest-MT (TMT) (Table 1), of these 848 sera $(96.6 \%)$ gave the same qualitative
Table 1 Comparative screening of 878 sera in the dye test (DT) and Toxotest-MT (TMT). Positive results have been taken as $>8 \mathrm{IU} / \mathrm{ml}$ in the $D T$ and $>1 / 16$ in the TMT. The percentage of sera in each group is also shown

\begin{tabular}{|c|c|c|}
\hline Results & Sera & $\%$ \\
\hline $\begin{array}{l}\text { Positive (both tests) } \\
\text { Negative (both tests) } \\
\text { Positive DT, negative TMT } \\
\text { Negative DT, positive TMT }\end{array}$ & $\left.\begin{array}{r}369 \\
479 \\
16 \\
14\end{array}\right\}$ & $\begin{array}{r}\left.\begin{array}{r}42.0 \\
54.6 \\
1.8 \\
1.6\end{array}\right\} 36.6 \\
3.4\end{array}$ \\
\hline Total & 878 & 100 \\
\hline
\end{tabular}

result in both tests while the remaining 30 sera $(3.4 \%)$ did not agree.

Quantitative studies were carried out on 339 sera and titres compared in the three test systems, the DT, TMT and IHAT. The results are shown in Table 2 for the DT and TMT, Table 3 for the IHAT and TMT and Table 4 for the DT and IHAT. Two badly haemolysed sera gave non-specific reactions in the IHAT, even after absorption, and have been omitted.

Negative sera in each test were treated as having a titre one dilution less than the threshold titre of that particular test-that is, negative DT $4 \mathrm{IU} / \mathrm{ml}$; negative TMT $1 / 8$; negative IHAT $1 / 32$, and regression lines were fitted to the data. ${ }^{14}$ In each case (Figs. 1, 2 and 3 ) the lines did not pass through the origin and the null hypothesis $\left(\mathrm{H}_{\mathrm{o}}: \beta=1\right)$ was rejected. This indicates that no two tests agreed, as when the regression lines drawn from the data were compared with a hypothetical line, the differences were significant $(p<0.005)$. The hypothetical line was calculated on the assumption that any two tests did agree and is governed by $\mathrm{H}_{\mathrm{o}}$ and the expression $\mathrm{y}=\beta \mathrm{x}$ (Table 5). There was a strong linear relation between the two variables with a high correlation coefficient $(r)$ in each case.

A measure of agreement between each combination of tests was calculated by estimating the percentage of the regression curve lying in the range of \pm 1 serial dilution (broken lines, Figs. 1, 2 and 3) from the hypothetical line. Using this parameter, the highest level of agreement was $78 \%$ between the DT and TMT, while the IHAT gave $66 \%$ and the DT and IHAT only $40.9 \%$ agreement.

\section{Discussion}

The TMT latex agglutination test was found to be very convenient, easy to use and simple to read when held against a dark background. The stable liquid antigen allows any number of tests to be run, without the problems associated with freeze-dried red cells which have a very limited life after rehydra- 
Table 2 Quantitative agreement of the TMT and DT for the detection of T gondii specific antibodies

\begin{tabular}{|c|c|c|c|c|c|c|c|c|c|c|c|c|c|}
\hline \multirow[t]{2}{*}{ Dye test $(I U / m l)$} & \multicolumn{13}{|c|}{ Toxotest-MT (reciprocal of titre) } \\
\hline & $<16$ & 16 & 32 & 64 & 128 & 256 & 512 & 1024 & 2048 & 4096 & 8192 & 16384 & Total \\
\hline$<8$ & 111 & 9 & 3 & & & & & & & & & & 123 \\
\hline 8 & 5 & 5 & 9 & 5 & & 1 & & & & & & & 25 \\
\hline 16 & 1 & 1 & 5 & 3 & 6 & & 1 & & & & & & 17 \\
\hline 31 & 2 & 2 & 14 & 8 & 13 & 1 & 3 & & & & & & 43 \\
\hline 62 & & & 3 & 9 & 9 & 6 & & 1 & 1 & & & & 29 \\
\hline 125 & & & 1 & 2 & 6 & 13 & 12 & 2 & & & & & 36 \\
\hline 250 & & & & & 1 & 7 & 3 & 3 & & & & & 14 \\
\hline 500 & & & & & & 4 & 3 & 4 & 4 & & & & 15 \\
\hline 1000 & & & & & & & 6 & $i$ & 1 & 1 & & & 9 \\
\hline 2000 & & & & & & 2 & 2 & & 1 & 2 & & & 7 \\
\hline 4000 & & & & & 1 & & 3 & 3 & 4 & 1 & & & 12 \\
\hline 8000 & & & & & & & & 1 & 2 & & & 6 & 9 \\
\hline Total & 119 & 17 & 35 & 27 & 36 & 34 & 33 & 15 & 13 & 4 & 0 & 6 & 339 \\
\hline
\end{tabular}

Table 3 Quantitative agreement of the TMT and IHAT for the detection of antibodies to $T$ gondii

\begin{tabular}{|c|c|c|c|c|c|c|c|c|c|c|c|c|c|}
\hline \multirow{2}{*}{$\begin{array}{l}\text { Indirect } \\
\text { haemagglutination test } \\
\text { (reciprocal of titre) }\end{array}$} & \multicolumn{13}{|c|}{ Toxotest-MT (reciprocal of titre) } \\
\hline & $<16$ & 16 & 32 & 64 & 128 & 256 & 512 & 1024 & 2048 & 4096 & 8192 & 16384 & Total \\
\hline$<64$ & 118 & 11 & 11 & 5 & 1 & 1 & & & & & & & 147 \\
\hline 64 & & 3 & 8 & 1 & & & & 2 & & & & & 14 \\
\hline 128 & & 1 & 12 & 9 & 7 & 7 & 2 & & & & & & 38 \\
\hline 256 & 1 & 1 & 1 & 6 & 13 & 6 & 7 & 1 & 1 & & & & 37 \\
\hline 512 & & & 1 & 5 & 14 & 13 & 10 & 4 & 2 & 1 & & & 50 \\
\hline 1024 & & & 2 & & 1 & 3 & 8 & 6 & 7 & & & & 27 \\
\hline 2048 & & & & 1 & & 3 & 6 & 2 & 1 & & & 1 & 14 \\
\hline 4096 & & & & & & & & & 2 & 2 & & 2 & 6 \\
\hline 8192 & & & & & & & & & & 1 & & 1 & 2 \\
\hline 16384 & & & & & & & & & & & & 2 & 2 \\
\hline Total & 119 & 16 & 35 & 27 & 36 & 33 & 33 & 15 & 13 & 4 & 0 & 6 & 337 \\
\hline
\end{tabular}

Table 4 Quantitative agreement of the DT and IHAT for the detection of antibodies to $T$ gondii

\begin{tabular}{|c|c|c|c|c|c|c|c|c|c|c|c|}
\hline \multirow[t]{2}{*}{ Dye test $(I U / m l)$} & \multicolumn{11}{|c|}{ Indirect haemagglutination test (reciprocal of titre) } \\
\hline & $<64$ & 64 & 128 & 256 & 512 & 1024 & 2048 & 4096 & 8192 & 16384 & Total \\
\hline$<8$ & 121 & & 1 & & & & & & & & 122 \\
\hline 8 & 11 & 6 & 8 & & & & & & & & 25 \\
\hline 16 & 2 & 1 & 11 & 3 & & & & & & & 17 \\
\hline 31 & 7 & 4 & 7 & 11 & 11 & 2 & 1 & & & & 43 \\
\hline 62 & 3 & 1 & 3 & 4 & 13 & 3 & 1 & & & & 28 \\
\hline 125 & 3 & & 2 & 12 & 9 & 6 & 4 & & & & 36 \\
\hline 250 & & & & & 7 & 2 & 5 & & & & 14 \\
\hline 500 & & 1 & 2 & 2 & & 8 & 1 & 1 & & & 15 \\
\hline 1000 & & 1 & 1 & 3 & & 2 & & 2 & & & 9 \\
\hline 2000 & & & 2 & & 2 & 1 & & 1 & 1 & & 7 \\
\hline 4000 & & & 1 & 2 & 7 & 1 & 1 & & & & 12 \\
\hline 8000 & & & & & 1 & 2 & 1 & 2 & 1 & 2 & 9 \\
\hline Total & 147 & 14 & 38 & 37 & 50 & 27 & 14 & 6 & 2 & 2 & 337 \\
\hline
\end{tabular}

tion. Although the recommended settling time is long, it is quite convenient to set up the test in the late afternoon and read the results the following morning.

As a screening test the TMT gave $96.6 \%$ agreement with the DT, with only $30 / 878(3.4 \%)$ of the sera giving a result which failed to agree in the two test systems.
A similar level of agreement $(94.4 \%)$ between the TMT and DT was reported by Kobayashi et al. ${ }^{15}$ These levels of agreement are better than those obtained when the DT and IHAT were compared. ${ }^{10}$ Only $54 \%(1072 / 1983)$ of the sera gave a result agreeing in both tests. The TMT appears to be a better substitute for the DT than is the IHAT for use as a screening test. 


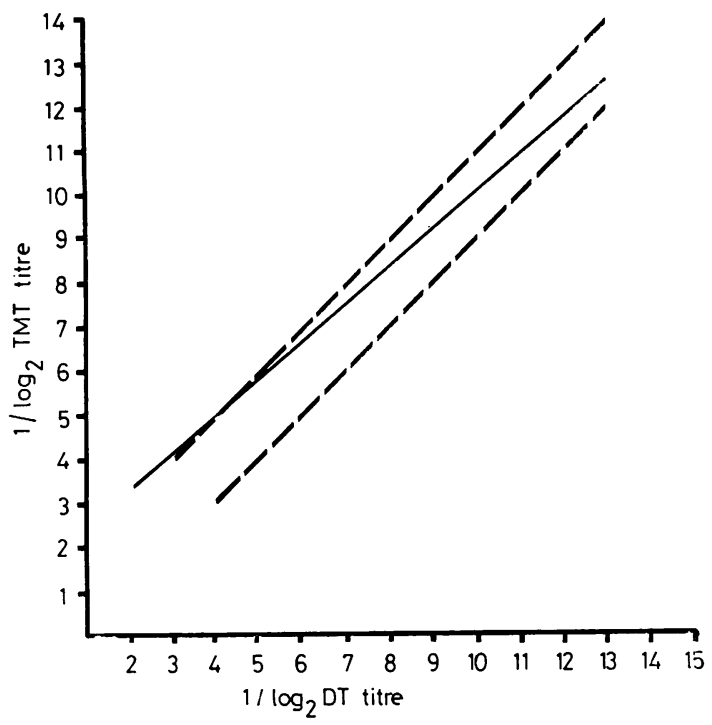

Fig. 1 Agreement between the DT and the TMT. The regression line $(-)$ and the limits of \pm 1 serial dilution about the hypothetical line (---) are shown. $78 \%$ of the regression line $(y=0.818 x+3 \cdot 491$, $r=0.911$ ) lies within the limits of the hypothetical line. In all three figures the limits of the hypothetical line are defined by the null hypothesis $\left(H_{o}: \beta=1\right)$ and the equation $y=\beta x \pm 1$.

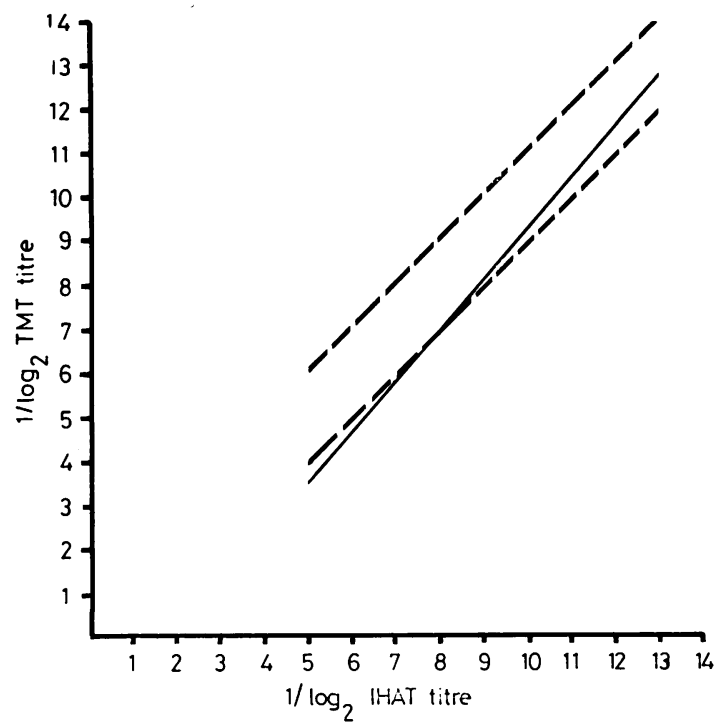

Fig. 2 Agreement between the IHAT and the TMT. The regression line $(-)$ and the limits of \pm 1 serial dilution about the hypothetical line (---) are shown. $66 \%$ of the regression line $(y=1 \cdot 143 x-2 \cdot 152$, $r=0.882)$ lies within the limits of the hypothetical line.

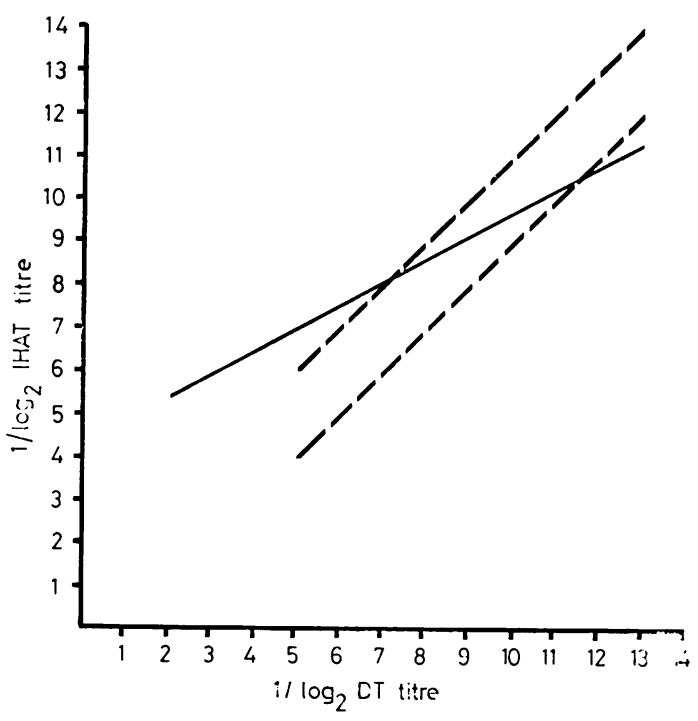

Fig. 3 Agreement between the DT and the IHAT. The regression line $(-)$ and the limits of \pm 1 serial dilution about the hypothetical line (---) are shown. $41 \%$ of the regression line $(y=0.556 x+4.266$, $r=0.803$ ) lies within the limits of the hypothetical line.

Table 5 Correlation coefficients, regression coefficients, $t$ test values and the probability of agreement with the null hypothesis $(p)$ for the regression lines drawn from the data

\begin{tabular}{lllrl}
\hline Variables & $* r$ & $\dagger b$ & \multicolumn{1}{l}{$t$} & $\ddagger p$ \\
\hline DT $v$ IHAT & 0.803 & 0.556 & 19.304 & $<0.005$ \\
DT $v$ TMT & 0.911 & 0.818 & 606.000 & $<0.005$ \\
IHAT $v$ TMT & 0.882 & 1.143 & 4.206 & $<0.005$ \\
\hline
\end{tabular}

*Correlation coefficient.

$\dagger$ Regression coefficient (slope of regression curve).

$\ddagger$ Probability of absolute agreement.

In the quantitative studies the TMT again showed better agreement with the DT $(78 \%)$ than did the IHAT $(40.9 \%)$, although the level of agreement was reduced in comparison to the quantitative studies. The IHAT showed better agreement with the TMT $(66 \%)$ than it did with the DT. These results indicate that antibody against a different pattern of immunogens is being measured in the three test systems examined.

The correlation coefficient $(r)$ was highest in the relation between the DT and TMT $(0.911)$. In this case, this can be regarded as an index of the reliability of the TMT to give consistent results against the DT, compared with the IHAT $(r=0 \cdot 803)$.

Recent studies have shown that three antigens 
(Ags 4, 5 and 6) are found in water soluble extracts of $T$ gondii prepared by hypotonic-lysis or sonication, while 11 antigens have been described when solubilising agents were used in the preparation. ${ }^{16} \mathrm{~A}$ soluble extract is used to sensitise the red cells in the IHAT system, so that antibody levels against the three internal antigens 4,5 and 6 will be measured by this test system. In the DT antibodies to all 11 antigens may potentially be measured, although antibodies to the surface antigens are more likely to be detected in this immune lysis system. TMT antigen was not available for evaluation by the immunoelectrophoretic techniques used in the previous study. ${ }^{16}$ It is unlikely, however, that all 11 antigens are present.

Immunisation studies are in progress using IHAT and TMT antigens to determine the pattern of antibody response produced against $T$ gondii immunogens present in these preparations.

Other studies are in progress to evaluate the TMT in the veterinary field, particularly for the diagnosis of ovine toxoplasmosis.

The TMT is convenient and simple to use and appears to be intermediate between the DT and IHAT in its specificity. The results it yields are likely to be more useful than those given in the IHAT which is of limited diagnostic value ${ }^{11}$ but further evaluation of the test in the routine laboratory is still required.

We are grateful to $\mathrm{Mr}$ Y Sawada of the Eiken Chemical Co Ltd, 1-33-8, Hongo, Bunkyo-Ku, Tokyo, Japan, for making the Eiken latex test (TMT) available to us.

Thanks are due to Mr Uthuba Hatari, Mr John Bridges and other Public Health Laboratory staff involved with this work.

\section{References}

${ }^{1}$ Sabin AB, Feldman HA. Dyes as microchemical indicators of a new immunity phenomenon affecting a protozoon parasite (Toxoplasma). Science $1948 ; 108: 660-3$.
${ }^{2}$ Feldman HA, Lamb GA. A micromodification of the dye test. J Parasitol 1966;52:415.

${ }^{3}$ Fleck DG, Kwantes W. The laboratory diagnosis of toxoplasmosis. Public Health Laboratory Service Monograph Series No 13; London, 1980.

' Walton BC, Benchoff BM, Brooks WH. Comparison of the indirect fluorescent antibody test and methylene blue dye test for detection of antibodies to Toxoplasma gondii. Am J Trop Med Hyg 1966;15, 2:149-52.

s Jacobs L, Lunde MN, A haemagglutination test for toxoplasmosis. J Parasitol 1957;43:308-14.

6 Jennis F. A simplified haemagglutination test for toxoplasmosis using pyruvic aldehyde treated cells. Aust $J$ Exp Biol Med Sci 1966;44:317-22.

- Hanaki T, Nobuto K. Sato U. Studies on hemagglutination for toxoplasmosis. Nippon Juigaku Zasshi 1964;26: 378-9.

${ }^{8}$ Hiraoka K, Ohshima S. Simplified hemagglutination test as a serologic test for toxoplasmosis. Jpn J Parasitol $1972 ; 21: 247-51$.

9 Thorburn H, Williams $\mathrm{H}$. A stable haemagglutinating antigen for detecting toxoplasma antibodies. $J$ Clin Patho! 1972;25:762-7.

${ }^{10}$ Balfour AH, Bridges JB, Harford JP. An evaluation of the ToxHA test for the detection of antibodies to Toxoplasma gondii in human sera. $J$ Clin Pathol 1980;33:644-7.

$"$ Welch PC, Masur H, Jones TC, Remington JS. Serologic diagnosis of acute lymphadenopathic toxoplasmosis. $J$ Infect Dis 1980;142, 2:256-64.

${ }^{12}$ Kwantes W, Payne RA, Ludlam GB, Bridges JB, Fleck DG. An assessment of a latex agglutination slide test for toxoplasma antibody. J Clin Pathol 1972;25:359-60.

13 Tsubota N, Hiroaka K, Sawada Y, Watanabe T, Ohshima S. Studies on latex agglutination test for toxoplasma. (2) Evaluation of the microtiter test as a serologic test for toxoplasmosis in man. Jpn J Parasirol 1977;26: 286-90.

${ }^{14}$ Snedecor GW, Cochran WG. Statistical methods. 6th ed. Iowa State University Press, 1967.

15 Kobayashi A, Hirai N, Suzuki Y, Nishikawa H, Watanabe $\mathrm{N}$. Evaluation of a commercial Toxoplasma latex agglutination test. Jpn J Parasitol 1977;26:175-80.

${ }^{16}$ Hughes HPA. Balfour AH. An investigation of the antıgenic structure of Toxoplasma gondii. Parasite Imniunol 1981;3:235-48.

Requests for reprints to: Dr AH Balfour, Public Health Laboratory, Bridle Path, York Road, Leeds LS15 7TR, England. 